\title{
L imites na construção de uma identidade política: condicionantes de gênero e de classe sobre o trabal ho docente na educação infantil
}

\author{
Hugo Leonardo Fonseca da Silva*
}

\begin{abstract}
R esumo: Este trabalho apresenta um conjunto de reflexões produzidas a partir de uma investigação sobre a identidade política das trabalhadbras da educação infantil na rede municipal de educação de Goiânia. As análises apontam para um intenso processo de feminização do trabalho dbcente na educação infantil e a identificação deste com o trabalho doméstico e a matemagem, inerentes aos papéis sociais historicamente desempenhados por mulheres. Indica ainda que essa atividade tem sofrido um processo de desprofissionalização, mediante sua identificação com uma pretensa "vocação feminina" que, ao naturalizar as relaçães de aridado e educação que o sexo feminino tem para com as crianças, desvaloriza essa atividade, reproduzindb a divisão entre reprodução e produção. Esses elementos constituem alguns dos condicionantes que dificultam a elaboração de uma identidade política, por parte dessas trabalhadbras, vinoulada aos interesses da classe traballhadbra.
\end{abstract}

Palavras-chave: identidade política; feminização do trabalho dbcente; educação infantil.

Introdução

A sinstituições de educação infantil têm sido caracterizadas, historicamente, pelo atendimento dos filhos e filhas de pais trabal hadores sob duas determinações centrais: a) liberar a força de trabalho feminina para o seu emprego no mundo do trabalho, seja na esfera da produção (fábricas) ou na da reprodução (trabal ho doméstico e demais atividades realizadas no setor de serviços); b) promover a sociabilização da prole das classes trabalhadoras, desde a mais tenra idade, para o exercício do trabalho alienado e da submissão e da subordinação em relação à ordem social (K uhlmann J R, 2001; Faria, 2002).

Essas instituições criadas no século XIX desenvolveram-se intrinsecamente vinculadas à história da mulher trabalhadora e da infância pobre, como aponta Faria (2002). N esse sentido, tais instituições tinham - e, em certa medida, ainda têm - um caráter educativo assistencialista que se estendeu às camadas populares, ora

\footnotetext{
* Professor da FEF-UFG e mestrando na FE-UFG.
}

como "dádiva" e "benesse" da I greja e das elites, ora como tutela estatal. A pedagogia assistencialista propugnada por essas instituições apresenta-se como um atendimento "pobre para os pobres", por intermédio de uma "pedagogia da submissão, uma educação assistencialista marcada pela arrogância que humilha para depois oferecer 0 atendimento como dádiva, como favor aos poucos selecionados para 0 receber" (K uhlmann JR, 2001, p. 183).

A agente central responsável pela materialização de tal atendimento seria a professora; mulheres "especialmente" educadas pelas técnicas pedagógicas e higiênicas provenientes dos avanços técnico-científicos de finais do século XIX e pelo "dom" e/ou "vocação natural" de mãe-educadora. Conformadas de maneira mistificadora, as professoras (jardineiras, pagens, tia etc.) eram, e ainda são, identificadas como educadoras natas portadoras de aptidões tais como amor, carinho, compreensão, meiguice, calma, paciência, autocontrole, praticidade e desprendimento (A rce, 2001). 
Como aponta Arce (2001), tais características são advogadas não só como pertinentes, mas como necessárias por pensadores que influenciam o campo de conhecimento e intervenção da educação infantil (dentre os quais destacam-se R ousseau, Froebel e M ontessori) e pelas legislações referentes ao atendimento educacional eassistencial para crianças menores de seis anos. No entanto, por detrás dessas diretrizes - políticas, teóricas e culturais - , são escamoteadas as relações de opressão de classe e de gênero a que essas trabalhadoras são submetidas e também a desprofissionalização e, conseqüentemente, a manutenção de um atendimento de baixa qualidade para as maiorias.

É fundamental destacar que o trabalho docente, especialmente na educação infantil e nas séries iniciais do ensino fundamental, reproduz a inserção subordinada que as mulheres têm, historicamente, sofrido no mundo do trabalho. Tal inserção caracteriza-se pela divisão sexual do trabal ho que, somada à divisão social hierárquica do trabal ho, explora duplamente a força de trabalho feminina, como aponta A ntunes (2002). A ssim, o exercício dessa atividade tem sido ideologicamente identificado com os processos de reprodução próprios do espaço privado do lar, ocupando um espaço marginal no interior das relações sociais, tanto economicamente como socialmente.

A identificação do trabalho docente na educação infantil como reprodução do trabalho doméstico envolve uma série de questões que interferem, e representam limites para tanto, na consti tuição de uma identidade política por parte dessas trabal hadoras, com um projeto histórico vinculado à tarefa histórica da classe trabal hadora de superação ativa do modo de produção capital ista. Neste texto destacamos duas: a primeira diz respeito à interpretação de que 0 processo de feminização do trabalho docente tem como eixo norteador a perspectiva de desprofissionalização dessas trabalhadoras, cujo caráter principal está na internalização de aspectos ideológicos subjacentes à identificação da atividade docente na educação infantil ao trabalho doméstico; e, em segundo lugar, que as divisões social e sexual do trabalho constituem e perpetuam a dicotomia entre produção e reprodução instituídas pelas relações sociais constitutivas do modo de produção capitalista, provocando divisão e concorrência no interior da classe trabalhadora e atingindo também as trabal hadoras da educação infantil.

Destacamos, ainda, o papel político e educativo do sindicato dos trabalhadores em educação, no sentido de superar as contradições provocadas pelos condicionantes do trabalho docente na educação (infantil) e de organizar coletivamente essa parcela da categoria, possibilitando a elaboração de uma identidade política vinculada aos interesses das classes trabalhadoras.

Por fim, é importante esclarecer que este texto é parte integrante de um trabalho de investigação que vem sendo realizado junto ao programa de Pós-Graduação em Educação B rasileira - UFG que tem como objetivo central compreender os limites e as possibilidades de construção da identidade política por parte das trabalhadoras em educação infantil na rede municipal de Goiânia.

A identidade das profissionais da educação infantil: entre a "vocação" feminina e o trabalho profissional

A s atividades profissionais nas instituições de educação historicamente estiveram vinculadas à inserção da mulher no mundo do trabal ho . 0 trabalho de educar e cuidar de crianças tem sido historicamente identificado como um prolongamento das atividades "naturais" que as mulheres desempenham no âmbito doméstico. Nesse sentido, a feminização ${ }^{1}$ do trabalho docente - em qualquer nível, mas com mais ênfase na educação infantil e nas séries iniciais - configura-se como um importante elemento na disseminação de uma ideologia que desmobiliza e busca engessar a organização coletiva dos trabalhadores da educação.

Essa lógica segue as determinações da inserção da mulher no mundo do trabal ho, que

1. Entende-se aqui por feminização o processo de naturalização das atividades que as mulheres desempenham socialmente (maternagem e trabalho doméstico), escamoteando o caráter de exploração de seu trabalho no seio de uma sociedade de classes. A feminização do trabalho docente é 0 fenômeno pelo qual predomina o trabalho do gênero feminino na área, caracterizando-o como uma vocação "natural" da mulher 
reúne os conflitos e contradições das questões de classe e de gênero. N ogueira (2004) observa que, com o advento do modo de produção capital ista, houve uma espécie de "inclusão" e "exclusão" da mulher no mundo do trabalho, conservando os elementos que configuravam as relações patriarcais, cuja dominação e opressão da mulher pelo homem é sua expressão mais manifesta.

Fazendo observações de que a família se caracterizou e se caracteriza como uma célula dessa sociedade, Nogueira (2004, p. 5) afirma que são reproduzidos no interior das relações "privadas" do lar os contornos dessa sociedade, cujo domínio patriarcal configurou-se como a primeira forma de dominação entre seres humanos.

Podemos entender que quando a família monogâmica espelha fielmente as suas raízes históricas, manifestando, claramente, o seu conflito entre o homem e a mulher em conseqüência da opressão masculina, temos uma amostra do antagonismo e das contradições da própria sociedade de classe, já que no espaço doméstico há um claro domínio patriarcal. (N ogueira, 2004, p. 5)

D estrinçando os caminhos que as mulheres têm percorrido no mundo do trabal ho ao longo da história, Nogueira $(2004$, p. 8) observa que historicamente a mulher vem desempenhando funções centrais na produção e na reprodução da sociedade e da vida. Entretanto, o trabalho da mulher torna-se público enfaticamente somente com o desenvolvimento das forças produtivas impulsionado pela sociedade burguesa. Foi com a R evolução Industrial, "junto com 0 advento da maquinaria, [que] deu-se 0 ingresso definitivo da mulher no mundo do trabalho".

0 incremento do capital fixo contribuiu para o aumento da exploração da mão-de-obra feminina no âmbito da produção fabril, colaborando expressivamente para 0 aumento da concorrência entre os trabalhadores e para a subtração de seus salários. Com base na divisão sexual do trabalho, os setores patronais dividem o valor da força de trabalho para toda a família e o rebaixam a valores menores ainda do que os correntes. 0 trabalho produtivo, que antes necessitava de valências físicas e de um contingente maior de força motriz (músculos humanos), com 0 advento da maquinaria precisaria somente de pessoas que se adaptassem às máquinas, requerendo um número cada vez menor de trabalhadores.

Nogueira (2004, p. 10) afirma que, dessa forma,

O capitalismo usa dessa divisão sexual do trabal ho para incentivar a competição entre os trabalhadores, rebaixando os salários em decorrência do ingresso da força de trabal ho feminina, incorporada à classe trabal hadora e percebendo salários ainda mais reduzidos.

A inserção da mulher no mundo do trabalho foi utilizada pelos donos dos meios de produção que, explorando o sentimento patriarcal, aumentaram a exploração de mais-valia duas vezes: explorando a força de trabalho feminina, que custa bem menos no mercado, e diminuindo os salários da força de trabalho masculina, que passou a concorrer com uma "mercadoria" mais barata.

M as, além da maquinaria e das explicações biologicistas ${ }^{2}$ sobre a pretensa inferioridade da força de trabalho feminina, quais outras características concorriam para que os salários das mul heres fossem bem menores no mercado de trabalho?

Nogueira (2004, p. 15) assevera que o fato de as mulheres ficarem com a incumbência do processo de reprodução no interior das relações domésticas limitaria sua dedicação profissional; e os baixos salários seriam uma forma de mantêlas cumprindo essas tarefas, não Ihes dando oportunidade de se especial izar em determinados ofícios.

No final século $X I X$ e início do século $X X$, a marcante presença da força de trabalho sexualmente segregada esteve baseada na divisão sexual do trabalho compreendida sob um ponto de vista "natural ista". A naturalização do

\footnotetext{
2. Segundo Nogueira (2004, p. 22), dentre as explicações que caracterizaram a força de trabal ho feminina como uma mercadoria de menor valor está a ênfase nas diferenças biológicas (morfofuncionais) entre homens e mulheres, baseadas, sobretudo, na sua "inferioridade" física e na capacidade de reprodução.
} 
trabalho da mulher significou também a definição daqueles que seriam os espaços e as profissões de mulheres. Nogueira (2004, apud Scott, 1994), observa que esse período se caracterizou por um intenso crescimento dos setores comerciais e de serviços públicos. 0 crescimento dos serviços públicos significou o emprego maior da força de trabalho feminina "para desenvolver funções como as de vendedoras de selos nos correios, de operadora nos telégrafos e nas tel efônicas, de enfermeiras nos hospitais e de professoras nas escolas" (grifos nossos).

Nesse sentido,

[...] o mundo do trabalho acentuou profundamente a divisão sexual do trabal ho, reservando para as mulheres espaços específicos que, na maioria das vezes, se caracterizavam pela inferioridade hierárquica, pelos salários menores e por atividades adaptadas a suas capacidades inatas. (Nogueira, 2004, p. 18, grifos nossos)

Esse é o caráter que 0 trabalho docente vai assumir no bojo da sociedade capital ista, ou seja, uma atividade a ser desempenhada por mulheres, pois se identifica com suas "capacidades inatas" de cuidar e educar crianças e jovens, devendo caracterizar-se por um baixo valor socioeconômico. A lém de oferecer um salário menor por se tratar de uma profissão feminina, o trabalho docente passa a carregar um fardo de ser uma atividade de menor valor social também.

N essa perspectiva, o magistério ${ }^{3}$ é compreendido como atividade inerente aos papéis sociais historicamente desempenhados pelas mulheres no âmbito privado familiar, resultando em uma profissão feminizada, de pouco valor social e econômico, definida pela "vocação natural" que as mul heres têm de educar e cuidar e que, portanto, não requer valorização nem tampouco organização política de suas trabal hadoras.

Entretanto, é necessário ressaltar que 0 magistério também significou uma forma de ascendência da mulher no mundo do trabalho.

\footnotetext{
3. A o usar o termo magistério, refiro-me ao trabalho docente em uma perspectiva ampliada, que caracteriza não só as professoras do ensino fundamental e médio, mas também as educadoras/professoras na educação infantil.
}

A possibilidade de sair de atividades laborais estafantes próprias das esferas produtivas ou dos trabalhos domésticos e a passagem de um trabal ho manual para um trabalho caracterizado pelo exercício intelectual significaram, na história da mulher trabal hadora, uma forma de "libertação" das fábricas, das relações patriarcais e uma pretensa elevação de status social.

Como aponta A pple (1995, p. 62).

As mulheres tinham muito pouca escolha ocupacional; e, comparada à maioria das alternativas - Iavanderia, costura, limpeza, ou trabalho na fábrica -, o magistério oferecia numerosos atrativos. Era 'distinto', pagava razoavel mente bem, e requeria pouca qualificação ou equipamento especial. Da segunda metade do século $[X X]$ em diante, também permitia viajar, viver independentemente ou na companhia de outras mulheres, atingir a estabilidade econômica e um status social modesto.

$\mathrm{Na}$ educação infantil, o caráter ascendente contrasta com o caráter descendente na profissão. Como apontam Cerisara (2002), Silva (2001) e Ongari e M olina (2003), com o advento das novas legislações para a educação infantil, que a caracterizaram como parte do sistema básico de ensino, passou a existir a necessidade da formação do pessoal que já trabalhava nas instituições. Para essas trabalhadoras, houve uma espécie de ascendência profissional engendrada pelo processo de formação a que foram submetidas e, conseqüentemente, pelas oportunidades de entrada no serviço por meio de concurso, melhores salários, planos de carreira etc. Já para as professoras que estavam inseridas na carrei ra docente, significou um processo de descendência na profissão, principalmente pel o fato de sair do ensino fundamental - espaço historicamente constituído com uma identidade institucional que tem caracterizado o ensino docente, a partir da concepção do ensino-aprendizagem - para a educação infantil.

Não obstante, a identificação ideológica dessa atividade com a domesticidade e como "lugar natural" da força de trabal ho feminina, no limite, reproduz as relações patriarcais no bojo da profissão no magistério, conduzindo o trabaIho docente a uma profissão inferior socioeconomicamente (A pple, 1995). 
0 trabalho docente vem se caracterizando como uma atividade femininizada, sobretudo nas séries iniciais e nas instituições de atendimento às crianças até seis anos. A ssim, é importante compreender que 0 atendimento educacional, seja na educação infantil ou na primeira fase do ensino fundamental, historicamente tem identificado o trabalho nesses espaços como uma atividade excl usivamente feminina, que, por sua vez, materializa-se como uma extensão das atividades domésticas. A caracterização do magistério, nessa visão, constitui o trabalho docente como uma "vocação natural" própria das capacidades "inatas" de mãe que são atribuídas às mulheres pelas relações sociais.

N esse sentido, Paula $(2002$, p. 4) observa que as concepções do magistério como vocação (ou sacerdócio) apontam para a legitimação da resistência à profissionalização do magistério. A ssim sendo,

[...] o processo de feminização transformou a profissão docente, especificamente a das séries iniciais do ensino fundamental [também nas creches e pré-escolas], num "trabal ho de muIher" pertinente aos papéis por elas tradicional mente desempenhados, como o cuidado de crianças e não conflitante com seu papel de esposa e mãe.

0 trabalho docente, especialmente aquele que lida com crianças até seis anos de idade, tem sido vinculado a um processo ideológico de identificação à maternagem e ao trabalho doméstico. ${ }^{4}$ Como observam Cerisara (2002), Ongari e M olina (2003), Silva (2001) e Alves (2002), as relações de trabalho próprias do espaço doméstico são elementos marcantes na composição da identidade profissional das trabal hadoras da educação infantil, situando-se, inclusive, como um espaço em que se conciliam trabal ho e os cuidados dos próprios filhos.

0 papel exclusivamente atribuído às mulheres de cuidar das crianças pequenas e educá-

\footnotetext{
4. Segundo Cerisara (2002, p. 37-38), maternagem é um termo, correntemente usado na literatura que aborda o tema gênero, que caracteriza os processos sociais de cuidado e educação das crianças em oposição à maternidade, que se refere à dimensão biológica da reprodução humana; trabaIho doméstico é referente às atividades desempenhadas no lar caracterizadas pela rotina, pelo acúmulo e pelas trocas de funções
}

las são expressas no depoimento de trabalhadoras que atuam na educação infantil na Rede M unicipal de Ensino de Goiânia (RMEG). ${ }^{5}$ Quando as trabal hadoras foram questionadas se suas atividades são atributos exclusivamente femininos, al gumas respostas confirmam essa compreensão, aparecendo da seguinte forma:

Sim, porque o trabal ho na educação infantil envolve, além da produção de conhecimento, cuidados íntimos que não seria agradável ser feitos por homens. Não se trata de preconceito e sim de preocupação. 0 cuidado com crianças depende de muita sensibilidade, jeito, conhecimento, que muitos homens não possuem. Cuidar de uma filha (principalmente na parte de higienização) pode ser permissível a um pai. Porém, esses cuidados feitos por estranhos [educador] podem trazer transtornos e/ou graves problemas. (PII 31)

A credito que seja pel os cuidados que devemos ter de mãe, a educação infantil exige isso de nós. (PII 20)

Sim, porque nessa faixa etária, além das atividades lúdicas, também tem a parte de higienização que se adequa mais à parte feminina; não querendo excluir o sexo masculino, mas principal mente porque as crianças menores, inclusive os bebês, exigem mais cuidados, e as mulheres têm mais habilidade nesse caso. (PI 26)

Outros depoimentos são imbuídos da perspectiva de que as instituições educacionais são extensão do lar, quando, dentre outras coisas, observam a necessidade do trabal ho masculino, no sentido de que estes se efetivem como referência masculina (pai) para as crianças.

Não, a criança precisa da presença masculina e feminina para formar sua personalidade. A través da convivência, diferenciar as diferenças entre os papéis/gêneros, apesar de conflitos de identidade sexual existentes no meio. (AE 16)

$N$ ão. Porque é necessário ter uma figura masculina para que as crianças possam se espel har ou até mesmo substituir a figura do pai. (AE 12)

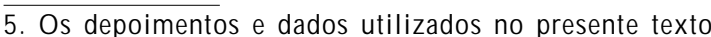
estão presentes no capítulo dois de um trabalho monográfico por nós desenvolvido em outra circunstância (cf. Silva, 2004). Utilizamos as siglas PI (professora magistério), PII (pedagoga) e AE (agente educativo) para identificar os sujeitos investigados, preservando suas identidades. 
As respostas das diferentes trabal hadoras das instituições de educação infantil da RM EG conformam-se à perspectiva de que o trabalho nesses locais se assemel ha muito às atividades domésticas, inclusive reafirmando a hegemonia dos papéis que a mulher desempenha como mãe e dona de casa e o homem, como referência do gênero masculino, no processo de construção de identidade da criança. A concepção e, mais, a materialização do trabal ho vinculado às tarefas domésticas ainda são um el emento constitutivo das instituições coletivas de atendimento educativo da infância, que hegemonicamente contam com mulheres exercendo suas atividades, ainda que as novas diretrizes políticas para a área apontem para uma vertical ização no seu aspecto pedagógico-educativo e uma heterogeneização no seu quadro pessoal.

J unto da hegemonia do gênero feminino no trabal ho docente na educação infantil, coexistem e se determinam mutuamente um outro elemento importante nas relações de trabalho nesses locais, que é a concepção das instituições como extensão do lar. Essa referência resguarda a idéia do senso comum de que o cuidado e a educação da criança menor de sete anos são tarefa da família ou dos pais, "cabendo ao Estado assumir a responsabilidade apenas quando as famílias não conseguem arcar com elas sozinhas" (Cerisara, 2002, p. 46).

Essa perspectiva denota o referencial do trabalho doméstico e da maternagem (característicos da concepção assistencialista) para o trabalho docente na educação infantil. $\mathrm{Na}$ atual conjuntura, as tensões entre casa-creche e creche-escola (Cerisara, 2002) não foram resolvidas; esse conflito é parte constituinte da identidade institucional da educação infantil que, por sua vez, significa um importante elemento na composição da identidade profissional das trabalhadoras dessa área.

A identidade profissional, ou seja, a compreensão de que se exerce um trabalho necessário à maioria da população brasileira, e de que tal trabalho deve se caracterizar pel o compromisso e pela competência técnica e política, é um fator preponderante na composição da identidade política das trabal hadoras da educação infantil.

$N$ esse sentido, a caracterização do trabal ho docente na educação infantil como uma "ativi- dade natural"|"vocação feminina" e das instituições coletivas de educação de crianças menores de sete anos como extensão do lar, contaminadas pelas práticas e ações inerentes ao papel de mãe e dona de casa, significa, entre outras coisas, a legitimação e a perpetuação da desprofissionalização dessas trabal hadoras.

A concepção das instituições de educação infantil como extensão do lar corrobora ainda com a perspectiva da divisão sexual do trabal ho e dos conseqüentes papéis de gênero diferenciados e hierarquizados que homens e mulheres exercem na sociedade. É importante observar que muitos dos depoimentos de professoras e agentes educativas demonstram uma concordância com a perpetuação da divisão sexual do trabal ho, segundo a qual os homens devem ocupar as chamadas atividades gerenciais no âmbito da educação, e às mulheres cabe a intervenção direta junto às crianças. Essa perspectiva marca justamente as características do trabal ho docente junto às crianças menores na primeira fase do ensino fundamental e na educação infantil.

Nesse sentido, há depoimentos de trabal hadoras que defendem o trabal ho de homens nas instituições, desde que não seja diretamente vinculado ao cuidado das crianças.

A s instituições infantis não são destinadas somente à al a feminina, pois existem trabal hos na própria instituição que são próprios do homem. Somente o que não pode ser feito pelo homem são os cuidados de higiene pessoal. 0 homem, hoje em nossa sociedade, já ocupa em seus lares o espaço reservado antes somente a mulheres, e em nossas instituições não vejo tanta necessidade desta divisão, somente de tarefas que deve haver. (PI 9)

Outra professora observa uma questão corrente nos Cmeis em Goiânia, que se configura pela presença masculina de forma indireta, geralmente ocupando cargos de direção, secretaria ou vigia.

Os Cmeis também têm funcionários homens que indiretamente, num momento ou outro, estão em contato com as crianças. (PII 7)

0 que nos chama a atenção nas respostas é a forma como as trabalhadoras auto-repre- 
sentam um laço doméstico e materno à sua profissão. I sso não é necessariamente um elemento negativo das relações de trabal ho na educação infantil, até mesmo porque tais relações são compositoras das formas de socialização no trabal ho docente junto às crianças menores de sete anos. Entretanto, quando confrontadas com o gênero masculino, as trabalhadoras tendem a perpetuar o patriarcalismo expresso na divisão sexual do trabalho, em que aos homens cabem os altos cargos e salários e as mulheres se "contentam" com cargos menos importantes e com gratificações menores.

A própria configuração da carreira docente expressa essa divisão sexual do trabal ho de forma hierarquizada. 0 número de mulheres é maior na educação infantil e nas séries iniciais do ensino fundamental, que se caracterizam como etapas menos valorizadas na carreira do magistério, enquanto tem aumentado significativamente 0 número de professores do sexo masculino na segunda fase do ensino fundamental e no ensino médio, no qual o trabal ho docente, além de exigir maior formação, tem sido historicamente mais val orizado, tanto social como economicamente (Codo et.al., 1999). Essa lógica segue a perspectiva da desqualificação do trabalho feminino que o modo de produção capitalista aprofunda e reproduz nos diversos campos que compõem o mundo do trabal ho.

Em estudos realizados pelo Instituto $\mathrm{Na}$ cional de Estudos e Pesquisas Educacionais (Inep) sobre os salários das diferentes ocupações na carreira do magistério no país, no ano de 2001, as diferenças salariais entre a primeira fase do ensino fundamental e da educação infantil em relação à segunda fase do ensino fundamental e o ensino médio são claras: a) educação infantil, média de $R \$ 422,78$ de salário; b) primeira fase do fundamental, $R \$ 461,67$ de média salarial; c) segunda fase do fundamental, $\mathrm{R} \$ 599,85$ de média sal arial; e d) ensino médio, $\mathrm{R} \$ 866,23$ de média salarial (M EC, 2003, p. 11).

Esses dados exemplificam a maior desvalorização do trabalho docente nas fases que se agrupam um maior número de mulheres, que têm baixa qualificação, o que, no limite, reflete as relações de contradições e conflitos existentes quanto à inserção da mulher no mundo do trabal ho, como uma força de trabal ho de menor valor.
A pple (1995, p. 33) chama a atenção para o fato de que, na carreira do magistério, há uma maioria de mulheres atuando no ensino primário e que uma parte considerável de homens ocupa cargos de direção e coordenação nas instituições escolares. Codo et.al. (1999) observam em uma pesquisa sobre a saúde do trabal hador da educação que, da educação infantil até o final do ensino fundamental, as mulheres predominam na atuação pedagógica, com 97,4\%. Esse predomínio é um importante fator da constituição da identidade dos trabalhadores da educação como categoria pela qual perpassa, inevitavelmente, a construção de suas identidades políticas.

Os dados obtidos nas instituições de educação infantil da RMEG demonstram a hegemonia do gênero feminino nas atividades docentes junto às crianças. D os questionários propostos, $100 \%$ foram respondidos por mulheres. A observação feita também aponta que as instituições constituem um local predominantemente organizado e dirigido por mulheres e cujo contigente de trabal hadores é majoritariamente feminino. Em apenas duas instituições, das vinte visitadas, havia homens (um em cada) cumprindo funções administrativas (secretários). A informação que obtivemos no Departamento de Educação Infantil (DEI) da Secretaria M unicipal de Educação é de que havia em toda rede que conta com 54 instituições administradas pela secretaria - apenas um homem trabalhando diretamente com a prática pedagógica na educação infantil.

A nalisando os números gerais do quadro de pessoal da Secretaria M unicipal de Goiânia, percebe-se o quanto essa relação de predomínio é evidente, o que significa dizer que, em um universo de 533 professores I, 4546 professores II e 310 agentes educativos, os quais lidam diretamente com os processos educativos das crianças, somente um professor do gênero masculino ${ }^{6}$ trabal ha no magistério na educação infantil. ${ }^{7}$

\footnotetext{
6. No processo de investigação, questionamos o pessoal do Departamento da Educação Infantil da SME sobre o número de professores do gênero masculino que lidam diretamente com crianças, obtendo a resposta de que somente um exercia o trabalho docente em um CMEI da rede.

7. Os números de professores I e II e de agentes educativos referem-se ao quadro geral da Secretaria de Educação do município de Goiânia, constando os professores que trabaIham tanto no ensino fundamental como na educação in-
} 
A questão da organização coletiva dos trabalhadores da educação (infantil) e da composição da identidade política desses trabal hadores sofre impactos perante a questão da feminização do local de trabalho. A correspondência do trabal ho nas instituições educativas com o trabalho doméstico e a contaminação das práticas educativas pelos processos maternoafetivos disseminam uma ideologia que desqualifica o trabalho e as funções dessas instituições, visto que cuidar e tratar de crianças até seis anos (no caso da educação infantil, mas essa faixa etária pode ser estendida até dez anos se forem agrupadas as séries iniciais do ensino fundamental) é tarefa da família e dos pais e mães, o que, para a sociedade, não se configura como trabal ho.

A ideologia da "vocação" feminina presente no trabalho docente desvaloriza socioeconomicamente essa atividade e suas trabal hadoras, tendo como lastro central a reprodução da dicotomia, provocada pelas relações sociais de produção capitalista, entre produção e reprodução. Essa cisão, além de configurar-se como um aspecto fetichizado das relações sociais, uma vez que concretamente não é possível materializar essa divisão, colabora na manutenção de certas expectativas, representações e estruturas de poder em relação ao gênero feminino, restringindo seu espaço de atuação ao privado (entendido como doméstico) ou a inserção subordinada no espaço público.

Como veremos a seguir, essas relações anteriormente descritas provocam limites objetivos e subjetivos às trabal hadoras da educação infantil, causando impactos sobre a percepção e a elaboração de idéias e ações diante dos conflitos sociais e educacionais, dificultando, assim, a construção de uma identidade política.

fantil (esses dados podem ter se modificado desde que nos retiramos do campo, em abril de 2004). Evidentemente que, no ensino fundamental, a caracterização do quadro de trabalhadores docentes é outra, pois as equipes são multiprofissionais, compostas de professores de outras áreas como matemática, educação física, artes, história etc., constituindo um campo de trabalho mais heterogêneo no que concerne à questão de gênero.
A dicotomia entre produção e reprodução e a construção da identidade política das trabalhadoras em educação infantil

De acordo com $M$ arx (1975, p. 98-99), o trabal ho no interior das relações sociais capitalistas somenteé considerado produtivo na medida em que produz mais-valia, ou seja, na medida em que se objetiva como valorização do capital, conformando-se como "trabalho socialmente determinado". N esse sentido, a reprodução das condições objetivas de valorização do capital, seja pela perpetuação da espécie humana (reprodução natural) ou pela reprodução da força de trabalho por meio de processos educativos, é marginal aos objetivos de auto-expansão e acumulação do modo de produção capitalista, provocando o que denominamos aqui de dicotomia entre produção e reprodução.

A dicotomia entre produção e reprodução própria dessa organização societal compreende o trabal ho doméstico como uma atividade invisível, que não tem val or, pois não produz mercadorias, o que conseqüentemente não contribui, de forma imediata, para a expansão do lucro.

M esmo havendo grande ênfase na domesticidade da mulher, reforçando o seu "estatuto social", o trabal ho doméstico não era considerado (e ainda nos dias de hoje esse debate se mantém) como trabalho, pois tratava-se de atividade desvinculada de relação econômica. (N ogueira, 2004, p. 24)

Como observa N ogueira (2004), a invisibilidade do trabal ho feminino gera dificuldades na busca de soluções para as difíceis condições de vida e trabalho da força de trabalho feminina, mantendo as mulheres material mente e ideologicamente como empregadas de segunda categoria. Essa invisibilidade influencia determinantemente o trabal ho nas instituições de educação infantil, criando obstáculos para a construção de uma identidade profissional das trabal hadoras desse setor de trabalho.

Cerisara (2004) ressal ta que os saberes e as práticas construídos ao longo da experiência, formação e do trabalho cotidiano pelas profissionais de educação infantil são descaracterizados por estarem diretamente ligados ao trabal ho familiar. 0 trabalho, nesse sentido, é 
considerado como atividade "prescindível", "acessória" e "complementar" às funções da família, que acabam desval orizando socialmente esse ofício, o qual não necessariamente precisa de uma formação específica, aprofundada e acadêmica. O u seja, apenas os aprendizados das tarefas de mãe/esposa/dona de casa inerentes aos processos de socialização da mulher na sociedade são suficientes para o trabal ho nas instituições de educação il nfantil.

A série de indefinições do campo da educação infantil relativas à formação, a quem são os profissionais que atuam na área, à identidade institucional (assistência x educação), além de outras questões, como a falta de financiamento definido para a pasta, reflete nas relações concretas de composição do quadro de trabalhadores na RMEG. Desde a implantação da educação infantil como um sistema de atendimento educativo à infância presente nas políticas educacionais do município de G oiânia, houve avanços e retrocessos na política de formação de quadros (recursos humanos) nas instituições de educação infantil.

A lves (2002) relata que, até o término de sua investigação, havia equipes multidisciplinares no interior das instituições de educação infantil, onde trabal havam, além das professoras pedagogas, professores de Educação Física e de A rtes, além dos agentes educativos. No ano de 2003 (já durante nossa investigação), a Secretaria M unicipal de Educação de Goiânia iniciou um processo de reestruturação do quadro de educadores nas instituições de educação infantil, retirando boa parte das professoras pedagogas e todas(os) professoras(es) de A rtes e de Educação Física (em que boa parte tinha qualificação em nível de pós-graduação latu e stricto sensu) da área, substituindo-as(os) por professoras com formação em magistério nível médio, empregadas em regime de contratos (emprego precarizado), e expressando assim dois determinantes: 1) a retomada da perspectiva de que 0 trabal ho na educação infantil não requer muita qualificação; e 2) um enxugamento dos gastos (já escassos) com a educação il nfantil.

Essas observações sobre as mudanças do quadro de profissionais que atuam na educação infantil demonstram a fal ta de definição sobre o que seja realmente 0 trabalho das educadoras nesse espaço, quais as suas especificidades, quais as necessidades de formação, se são atividades "naturalmente" desenvolvidas por mulheres ou se requerem a profissionalização de suas trabalhadoras, a qual passa necessariamente pela qualificação inicial e em serviço, por melhores condições de vida e trabalho, por planos de carreira estabeleci dos, pela realização de concursos públicos. Enfim, pela materialização de uma política que democratize realmente a educação infantil com uma qualidade socialmente referendada.

Tais conquistas têm sido historicamente garantidas pela organização política dos trabaIhadores e pela afirmação de uma identidade política del es diante dos conflitos e das contradições que o sistema capitalista impõe à vida das maiorias. A s bandeiras de luta anteriormente referidas são levantadas desde meados da década de 1970 pelos trabalhadores da educação, quetêm se organizado em sindicatos, unindo suas forças aos interesses de toda a classe trabal hadora brasileira (Ribeiro, 1987) e construindo uma identidade política engajada ao projeto histórico de transformação dessa sociedade, engendrado pela classe que vive do trabal ho.

0 processo de organização política dos trabalhadores da educação tem criticado profundamente a caracterização do trabalho docente como uma vocação feminina, como uma forma corrosiva do agir coletivo dessa categoria. A djetivar o trabal ho docente como uma atividade "natural" da mulher, e, portanto, uma atividade de menor valor social e econômico, reproduz a divisão estabelecida entre produção e reprodução que tem se constituído como elemento que torna heterogênea e fragmenta a classe que vive do trabal ho.

Essa dicotomia que caracteriza a divisão sexual do trabalho é "uma construção simbólica e social produzida na esfera da produção e reprodução", as quais, na realidade, atuam de forma estreitamente articulada, ainda que 0 atual sistema societal as apresente de forma separada e distinta (M ascarenhas, 2002, p. 22).

Desconstruir as concepções do trabalho feminino nos espaços educativos que atendem a crianças menores de sete anos como uma atividade "natural" significa também (re) construir a compreensão do trabalho realizado na 
esfera doméstica por esses mesmos atores sociais, que são as mulheres. A recusa da falsa dicotomia entre produção e reprodução significa a negação das formas burguesas de relações, que são determinantes tanto na esfera doméstica quanto nos diversos locais de trabal ho.

A construção da identidade política das trabalhadoras da educação infantil lida com essa negação e com a afirmação das instituições como local de trabal ho onde suas trabal hadoras prestam serviços complexos e importantes, que necessitam de qual ificação e de salários compatíveis. A firmar, pela conquista e pela luta, 0 trabalho na educação infantil como profissão significa negar os condicionantes ideológicos que desvalorizam a força de trabal ho feminina, articulando as contradições e conflitos de gênero às lutas contra as formas de opressão universal impostas pela sociedade de classes.

0 enfrentamento dessa contradição é, como afirma M ascarenhas (2002), uma das condições fundamentais da reconstrução da solidariedade de classe e da constituição de formas de resistência e de oposição da classe trabal hadora organizada diante do capitalismo tardio. Portanto, a retomada do fôlego das organizações político-sindicais como forma autêntica e necessária de organização e educação política da classe trabalhadora não pode desconsiderar as questões de gênero e da feminização do mundo do trabalho.

Nesse sentido, os sindicatos docentes não podem fugir a esse debate, uma vez que contam com uma categoria profissional composta em sua maioria por mulheres. Por outro lado, é de fundamental importância que as trabal hadoras da educação infantil insiram-se nesse movimento, buscando assenhorar-se da sua história e provocar o debate sobre as suas particularidades no interior da organização dos trabalha dores em educação.

\footnotetext{
Abstract: This study aims at presenting a set of considerations about the investigation of political identity of teachers of children for the municipal schools of Goiânia. The analysis shows a great process of feminization in the work of teaching children. It demonstrates how the practice is identified with house working and motherhood, which are inherent to the
}

historical social role fulfilled by women. It also reveals a process of loss of professionalization due to the claim of "feminine vocation". The activity is devalued when the relation between care and education that females have to children is naturalized, reproducing the division between reproduction and production. These elements are constituted as conditioners that difficult the elaboration of a political identity, by these workers, linked to the working class interests.

K ey words: political identity; feminization in teaching; children education.

\section{Referências}

A LVES, N ancy N onato de Lima. Elementos mediadores e significados da docência em educação infantil na rede municipal de ensino de Goiânia. Goiânia, 2002. Dissertação (M estrado em Educação B rasileira) - Faculdade de E ducação, U FG.

ANTUNES, Ricardo. Os sentidos do trabalho: ensaio sobre a afirmação e negação do trabal ho. 5. ed. São Paulo: B oitempo, 2002.

A R CE, A lessandra. D ocumentação oficial e o mito da educadora nata na educação infantil. Caderno de Pesquisa. São Paulo, n. 113, p. 167-184, jul/2001. Disponível em: http://www.scielo.org. A cesso em: 23 nov. 2005

A PPLE, Michael. Trabalho docente e textos: economia política das relações de classe e de gênero em educação. Porto A legre: A rtes M édicas, 1995.

BRASIL/M EC. Professor. B rasília, ano 1, n. 1, 2003.

CERISARA, B eatriz. Professoras de educação infantil: entre o feminino e o profissional. São Paulo: Cortez, 2002.

CODO, Wanderley et.al. Educação: carinho e trabal ho. 3. ed. Petrópolis: Vozes, 1999.

FARIA, A na Lúcia G. de. Educação pré-escolar e cultura: para uma pedagogia da educação infantil. 2. ed. Campinas: Edunicamp; São Paulo: Cortez, 2002.

KUHLMANN JR., M oysés. Infância e educação infantil: uma abordagem histórica. 2. ed. Porto A legre: Editora M ediação, 2001.

MARX, Karl. Capítulo inédito d'O Capital: resultados do processo de produção imediato. Porto: Publicações Escorpião, 1975.

M A SCA RENHAS, Ângela Cristina B. 0 trabalho e a identidade política da classe trabalhadora. Goiânia: EditoraA Iternativa, 2002.

NOGUEIRA, Cláudia Mazzei. A feminização do mundo do trabalho. Campinas: A utores A ssociados, 2004. 
ONGA RI, Bárbara; M OLINA , Paola. A educadora de creche: construindo suas identidades. São Paulo: Cortez, 2003.

PA ULA, Lucília A ugusta Lino de. A identidade profissional e a corrosão do caráter: efeitos do neoliberalismo no magistério. Goiânia: A nais do Endipe, 2002.

RIBEIRO, M aria Luisa Santos. A formação política do professor de $1^{\circ}$ e $2^{\circ}$ graus. Campinas: Autores A ssociados, 1987.
SILVA, Hugo Leonardo F. da. A identidade política das trabalhadoras da educação infantil da rede municipal de Goiânia. Goiânia, 2004. M onografia (Especialização em Educação Infantil) - Faculdade de Educação, UFG.

SILVA, I sabel de Oliveira. Profissionais da educação infantil: formação e construção de identidades. São Paulo: Cortez, 2001. 
